\title{
Analysis of the silicon market: Will thin films profit?
}

\author{
W.G.J.H.M. van Sark ${ }^{\mathrm{a}, *}$, G.W. Brandsen ${ }^{\mathrm{a}}$, M. Fleuster ${ }^{\mathrm{b}}$, M.P. Hekkert ${ }^{\mathrm{c}}$ \\ ${ }^{a}$ Department of Science, Technology and Society, Copernicus Institute for Sustainable Development and Innovation, \\ Utrecht University, Heidelberglaan 2, 3584 CS Utrecht, The Netherlands \\ ${ }^{\mathrm{b}}$ Solland Solar Energy, Bohr 10, 6422 RL Heerlen, The Netherlands \\ ${ }^{\mathrm{c}}$ Department of Innovation Studies, Copernicus Institute for Sustainable Development and Innovation, \\ Utrecht University, Heidelberglaan 2, 3584 CS Utrecht, The Netherlands
}

Received 6 September 2006; accepted 11 December 2006

Available online 30 January 2007

\begin{abstract}
The photovoltaic industry has been growing with astonishing rates over the past years. The supply of silicon to the wafer-based industry has recently become a problem. This paper presents a thorough analysis of the PV industry and quantifies the silicon shortage. It is expected that this leads to a decrease in production in 2006 rather than the usual increase. Due to a mismatch in expansion plans of silicon feedstock manufacturers and solar cell manufacturers, a large cell overcapacity will persist up to 2010 . The thin-film PV market is expected to profit from the silicon shortage problem; its market share may substantially increase to about $25 \%$ in 2010 .
\end{abstract}

(C) 2007 Elsevier Ltd. All rights reserved.

Keywords: Market development; Silicon feedstock; Thin films

\section{Introduction}

For many years now, the photovoltaic (PV) market has been growing with double-digit growth rates. The most recent market survey on cell and module production, annually performed by a.o. the magazine Photon International, reports a cell production capacity in the year 2005 of $1.8 \mathrm{GWp}$ (Hirschman and Schmela, 2006), and an average growth rate of $45 \%$ annually between 1999 and 2005 , which per chance equals the growth rate of 2005 . The cumulative worldwide installed capacity now exceeds $6 \mathrm{GWp}$. As most of the solar cells $(93.5 \%)$ are produced from silicon wafers, the large growth in 2005 was not expected due to a possible silicon feedstock shortage. Moreover, a 4\% increase has occurred in average module price since mid-2004 (Solarbuzz, 2006), at which time this price was at it lowest point of $5.6 € / \mathrm{Wp}$. Note that this is based on single-module list prices; for systems modules are sold in bulk, resulting in typical prices about half of that. As the thin-film PV industry does not suffer from the

\footnotetext{
*Corresponding author. Tel.: + 31302537611 ; fax: + 31302537601 .

E-mail address: W.G.J.H.M.vanSark@chem.uu.nl (W.G.J.H.M. van Sark).
}

present scarcity of silicon, it is legitimate to ask whether the thin-film PV industry may profit from the silicon feedstock problem (Rogol and Fisher, 2005; Unzalu, 2005; Green, 2006; Hegedus, 2006; Swanson, 2006). We studied this issue by thoroughly analysing the present (updated until April 2006) and future (2010) PV market. To this end, we scanned and summarized available (grey) literature, press releases and internet resources pertaining to silicon suppliers and PV manufacturers, with focus on expansion plans. We will present results in an aggregated form.

\section{Analysis}

\subsection{Silicon feedstock}

The availability of silicon feedstock is acknowledged as a critical issue in keeping up the high industry growth rates up to the levels of the present time. At present, nine silicon producers are supplying high-purity silicon to the photovoltaic and semiconductor industry, and their annual production sums up to $35.7 \mathrm{kton}$ for 2006 . Fig. 1 presents the aggregated data. Up to 2005 , built-up reserves in previous years in combination with a growth in feedstock production capacity allowed PV cell manufacturers to 


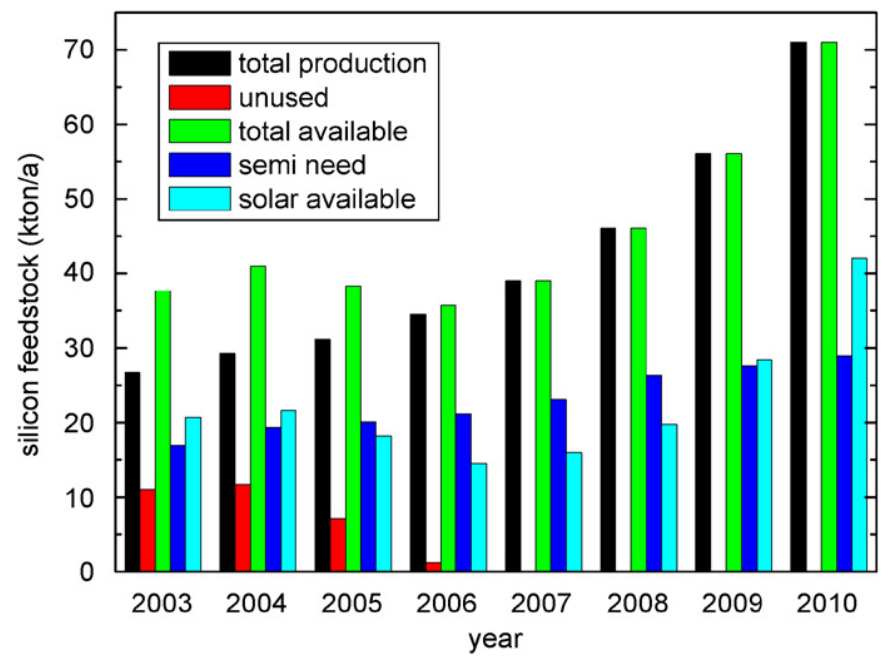

Fig. 1. Development of silicon feedstock production and unused feedstock in kton/a and availability for the semiconductor and PV industry until 2010 .

reach the $1.8 \mathrm{GWp}$ capacity level at the end of 2005 . However, the availability of silicon for the PV industry is limited due to the needs of the semiconductor industry. Moreover, as the products of the semiconductor industry represent a much larger value per area of product than solar cells, this industry can easily afford to pay higher prices to the feedstock manufacturers. As a consequence, the PV industry depends on the needs of the semiconductor industry. As depicted in Fig. 1, the needs of the semiconductor industry steadily increase at about $8 \%$ annually in the period 2003-2010. In contrast, a clear decrease in silicon availability is apparent in 2006 and 2007: 14.5 and 16 kton, respectively, are available for solar cells, while in earlier years around $20 \mathrm{kton}$ was available. Due to the high investments and long building times of new feedstock production facilities, new production plans stated in 2006 are expected to be realized from 2008 onwards, while full production capacity will be reached half a year later due to a start-up phase. This gives rise to the silicon shortage for the years in between, with a possible further increase in module price as a consequence. Table 1 shows production capacity data per producer, including plans up to 2008. For 2009 and 2010, we expect 3000 and 15,000 kton extra capacity, respectively. These expansion plans are estimated to lead to $42 \mathrm{kton}$ of silicon being available for solar cells in 2010 , or three times more than in 2006.

\subsection{Cell production capacity}

The silicon demand by the PV cell industry can be estimated using the available amount of silicon in combination with the amount of silicon needed to produce $1 \mathrm{MWp}$ of solar cells. In 2003, 14 ton of silicon were needed per MWp. Due to efficiency improvements (from $14 \%$ in 2003 to $17 \%$ in 2010 ) and the use of thinner wafers (from $320 \mu \mathrm{m}$ in 2003 to $150 \mu \mathrm{m}$ in 2010 ), it is expected that in 2010 this amount will be nearly halved to 7.5 ton/MWp
Table 1

Production capacity at the end of 2006, 2007 and 2008

\begin{tabular}{lccc}
\hline Silicon producers & \multicolumn{2}{l}{ Production capacity (kton) } \\
\cline { 2 - 4 } & 2006 & 2007 & 2008 \\
\hline Hemlock Semiconductor & 10 & 11 & 14.5 \\
REC Silicon & 6 & 7.2 & 10.7 \\
Wacker Polysilicon & 5.5 & 6.5 & 8.5 \\
Tokuyama Corporation & 5.4 & 5.4 & 8.4 \\
MEMC & 3.7 & 3.7 & 3.7 \\
Mitsubishi Polysilicon & 2.8 & 2.8 & 2.8 \\
Sumitomo Titanium & 0.7 & 0.7 & 0.7 \\
Xinguang & 0.3 & 1.25 & 1.25 \\
Joint Solar Silicon (JSSI) & 0.1 & 0.5 & 1 \\
Surplus & 1.2 & & - \\
Extra expected & & & 1.5 \\
Total & 35.7 & 39.05 & 53.05 \\
\end{tabular}

Actual running capacity may be lower when new capacity is added, due to assumed half-year start-up phase.

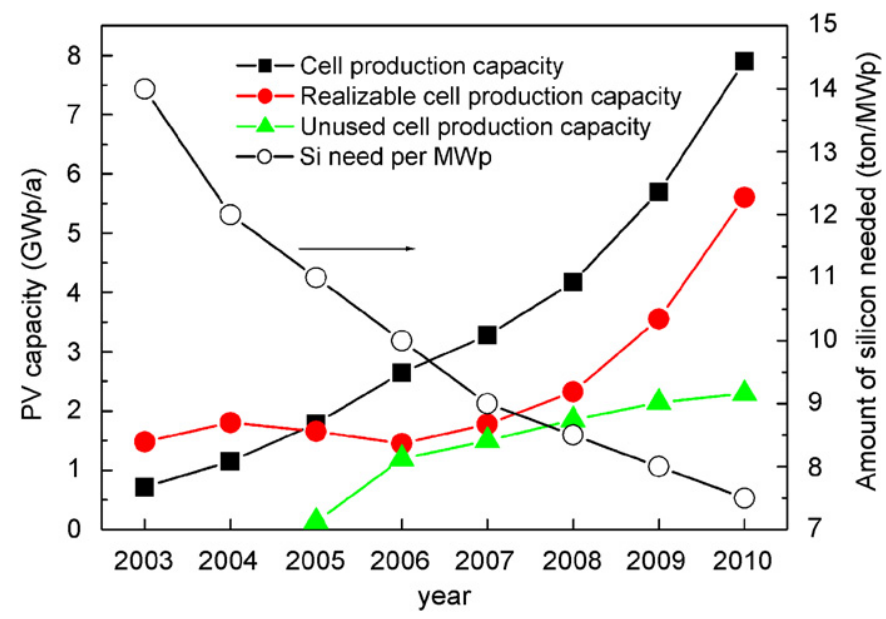

Fig. 2. Production and realized PV cell production capacity and apparent overcapacity (unused cell production capacity) until 2010 in GWp/a for wafer-based silicon cell technology. Also the amount of Si needed (ton/ MWp) is shown, which is halved in 7 years.

(Unzalu, 2005), see also Fig. 2. Similar figures are reported by others (Rogol and Fisher, 2005; Swanson, 2006). Fig. 2 also compares the resulting realizable cell production capacity with the actual (2002-2005) and estimated (2006-2010) production capacity. We define realizable cell production capacity as the capacity that can be realized with the amount of silicon feedstock available. In the years before 2005, the realizable cell production was larger than the cell production capacity. Occurring for the first time in 2005 , the realizable cell production was about equal to the cell production capacity, i.e., 1.8 GWp. Clearly, and alarmingly, a very large overcapacity in cell production is expected to occur in 2006 and 2007, which may lead to the fact that about half of the cell production capacity cannot be used. There simply is not enough silicon available, and the annual realizable cell production in 2006 will be lower than in 2005, estimated at $1.5 \mathrm{GWp}$. In 2007, the annual realizable cell production will return to the same level as in 
2005 and will further increase to $5.6 \mathrm{GWp}$ in 2010 . The silicon shortage will certainly have its repercussions on future capacity investment plans and decisions, and lead to an expected decrease of annual solar-cell production in 2006 rather than the usual increase. Solar cell manufacturers should pursue strong links with silicon feedstock producers to ensure long-term delivery contracts, and many have done so. It may also lead to shakeout and bankruptcy in the PV industry. Beyond 2007, there still will be a cell-making overcapacity, although amounting to about $1 / 3$ of the cell production capacity in 2010 . This should prompt silicon feedstock producers to expand even more than they plan today, taking into account that plans today materialize 2 years later.

\subsection{PV emerging thin-film market}

The present thin-film PV market share at the end of 2005 is about $6.5 \%$ of the total $1.8 \mathrm{GWp}$, and comprises the material systems amorphous silicon (a-Si), copper indium gallium selenide (CIGS) and cadmium telluride (CdTe). Their shares in 2005 are $64 \%, 10 \%$ and $26 \%$, for a-Si, CIGS and CdTe, respectively. Our analysis of the expansion plans of the thin-film PV manufactures shows a 10fold increase from the present production capacity of $170 \mathrm{MWp}$ to $1.8 \mathrm{GWp}$ in 2010, as depicted in Fig. 3. This enormous increase is due to double-digit growth rates of the thin-film industry, which we found to be over $60 \%$. Table 2 lists the expected production capacities per company at the end of 2006 and 2007. For production capacities in later years, we assumed the annual growth rates of $60 \%, 80 \%$ and $70 \%$, for a-Si, CIGS and CdTe, respectively, based on historical trends. Market shares of a$\mathrm{Si}, \mathrm{CIGS}$ and CdTe in 2010 are estimated to be about $60 \%$, $20 \%$ and $20 \%$, respectively, making clear that the CIGS market is expected to grow faster than the other thin-film market segments.

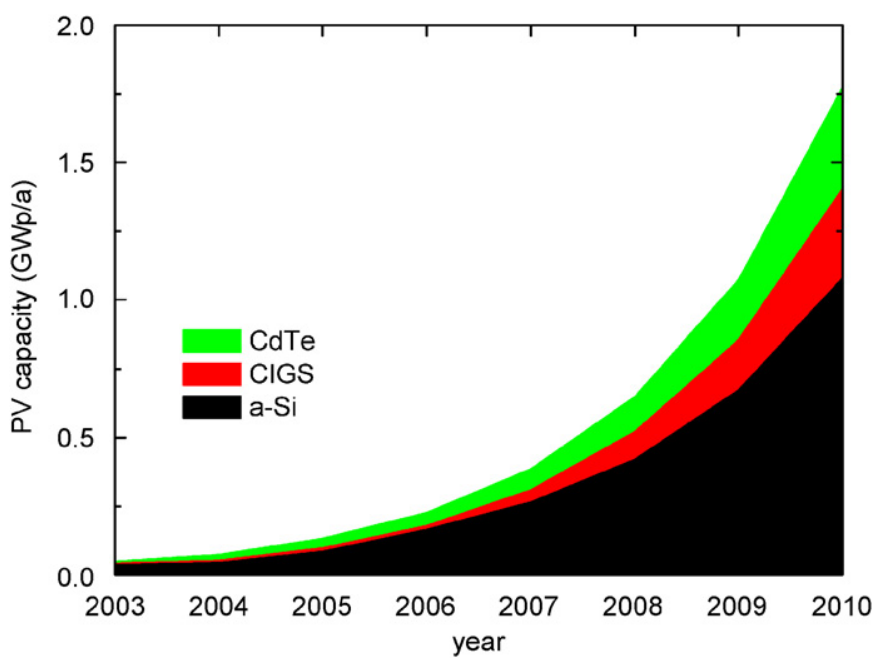

Fig. 3. Production capacity until 2010 in GWp/a for thin-film PV technology.
Table 2

Cell production capacity for thin-film producers at the end of 2006 and 2007

\begin{tabular}{|c|c|c|}
\hline \multirow[t]{2}{*}{ Thin-film producer } & \multicolumn{2}{|c|}{ Production capacity (MWp) } \\
\hline & 2006 & 2007 \\
\hline \multicolumn{3}{|l|}{$\mathrm{a}-\mathrm{Si}$} \\
\hline Bangkok solar & 12 & 12 \\
\hline EPOD & & 8 \\
\hline Energy Photovoltaics Inc. & 2.4 & 2.4 \\
\hline Free Energy Europe & 1.2 & 1.7 \\
\hline Fuji Electric Systems & 18 & 18 \\
\hline Heliodomi SA & 3 & 3 \\
\hline ICP Solar Technologies Ltd. & 3 & 3 \\
\hline Kaneka & 30 & 55 \\
\hline Mitsubishi Heavy Industries & 50 & 70 \\
\hline Schott Solar & 3 & 30 \\
\hline Sharp & 15 & 15 \\
\hline Sinonar & 3 & 3 \\
\hline Solar Cells Ltd. & 1.2 & \\
\hline TerraSolar & 2.5 & 2.5 \\
\hline Tianjin Jinneng Solar Cell & 1.6 & \\
\hline United Solar Ovonic & 50 & 100 \\
\hline CSG Solar & 12 & 25 \\
\hline \multicolumn{3}{|l|}{$\mathrm{CdTe}$} \\
\hline Antec Solar Energy & 20 & 20 \\
\hline First Solar & 40 & 75 \\
\hline \multicolumn{3}{|l|}{ CIS/CIGS } \\
\hline Daystar Technologies Inc. & 2 & 2 \\
\hline Global Solar Energy & 1.7 & 2 \\
\hline Honda & 2.8 & 28 \\
\hline Miasole & 5 & 5 \\
\hline \multicolumn{3}{|l|}{ Shell Solar } \\
\hline Showa Shell Sekiyu & & 20 \\
\hline Sulfurcell & 1.5 & \\
\hline Wuerth Solar & 1.5 & 15 \\
\hline Total a-Si & 207.9 & 348.6 \\
\hline Total Cd-Te & 60 & 95 \\
\hline Total CIS/CIGS & 14.5 & 72 \\
\hline Total thin film & 282.4 & 515.6 \\
\hline
\end{tabular}

Actual running capacity may be lower when new capacity is added, due to assumed start-up phase.

Although the thin-film share of the total PV market had been decreasing from $13 \%$ in 1999 (Hirschman and Schmela, 2006) to the present $6.5 \%$, our analysis shows that the thin-film PV industry is ready to sustain a much larger market share in the near future. Fig. 4 compares the PV capacity data from Figs. 2 and 3 for wafer-based silicon and thin films. The wafer-based silicon market suffers from a disruption in the growth in 2006 and 2007, while the thinfilm maintains the very high growth rates in these and later years. This leads to a thin-film market share of about $25 \%$ in 2010 .

\section{Discussion}

The silicon shortage presented here is larger than that reported in other analyses (Rogol and Fisher, 2005; Unzalu, 2005), probably due to differing assumptions. 


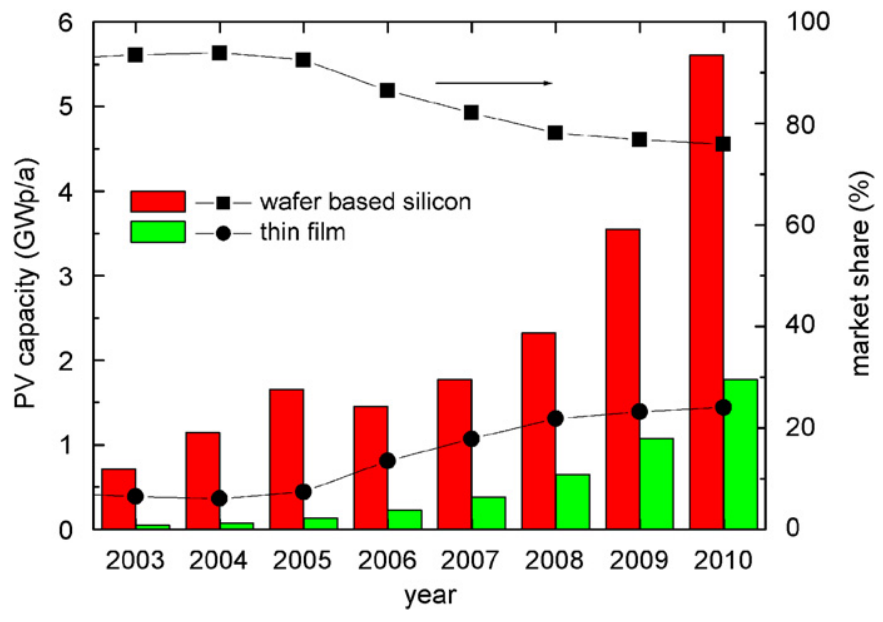

Fig. 4. Production capacity until 2010 in GWp/a and market share for wafer-based silicon and thin-film PV technology.

For example, in contrast to Rogol and Fisher (2005) we assume that an expansion plan for a feedstock manufacturer will be realized in a certain year, say 2008, but it will run at full capacity half a year later (start-up phase). The full capacity should therefore not be counted in the year in which it was realized. As a consequence, our estimates of silicon production seem "delayed" compared to others. Similarly, this also holds for solar cell manufacturers, although realization times and start-up phase are considerably shorter. Other explanations of the found differences are difficult to substantiate, as data per manufacturer were not reported by Rogol and Unzalu.

The thin-film market share presented here is larger than others report. Rogol's estimate of the thin-film market is $0.5 \mathrm{GWp}$ in 2010 (Rogol and Fisher, 2005), Unzalu's estimate is $1 \mathrm{GWp}$ (Unzalu, 2005). In their view, the waferbased market will grow to 5.5 and $4 \mathrm{GWp}$, respectively, leading to thin-film market shares of $8 \%$ and $20 \%$ in 2010 . Rogol relates this low thin-film market share to the competitive advantage that wafer-based companies have, regarding dominance and possible cost reductions. Thinfilm companies are beginning to enter the market, and will increase their share, but only modestly. However, our analysis shows that growth rates of the thin-film industry are over $60 \%$ and they will continue to be larger than for the wafer-based market.

Regardless of the differences of our analysis with others in terms of absolute numbers, the silicon feedstock shortage remains a problem, which is difficult to solve on the short term. As the thin-film PV industry does not suffer from the silicon feedstock problem, we expect that it may profit from it. However, as becomes clear from Fig. 4, the increase in market share flattens off in 2010, and an even larger increase in production capacity would be needed to continue the growth in market share. The question remains open whether that would be possible. As Green (2006) recently argues, the silicon feedstock problem may give the thin-film industry the chance of breaking through the 'lock- in' barrier. Even though it was suggested in 2000 that "thin films are about to dominate the PV industry" (Andersson and Jacobsson, 2000), wafer-based silicon still is the dominant design for PV, as was identified about a decade earlier (Utterback and Suárez, 1993). Utterback and Suárez (1993) also stated that this is likely to remain so due to the vested interests in this technology and the experience build up over the years. With current market increase this statement still holds. However, since material constraints do not exist for thin-film technologies (Andersson, 2000), and long-term potential module manufacturing costs are estimated to be as low as half the wafer-based module costs, i.e., $0.2 € / \mathrm{Wp}$ (Zweibel, 2005), the now apparent silicon feedstock problem may very well lead to an accelerated breakthrough of thin-film technology (Swanson, 2006). This is an important observation since it may very well give PV manufacturers that invest in thinfilm production capacity a competitive advantage over other producers. Between the thin-film materials, we do not expect a dominant design in the short term, although presently, a-Si has the largest market share. It may well be so that the prospects of reaching higher efficiencies at low cost are in favour of CIGS and CdTe (Andersson and Jacobsson, 2000). To be best prepared for sudden changes in the environment like the described silicon problem, the PV industry as a whole should strive for a diverse technology approach.

\section{Conclusion}

A thorough analysis of publicly accessible information sources on the PV industry has led to a quantification of the present silicon feedstock problem. The shortage of silicon is expected to lead to a decrease in production in 2006 rather than the usual increase. Expansion plans of silicon feedstock manufacturers are not synchronized with the expansion plans of solar cell manufacturers, which causes a large overcapacity to persist up to 2010. The thinfilm PV market is expected to profit from the silicon shortage problem; its market share will substantially increase to about $25 \%$ in 2010 . Investments in thin-film production capacity are likely to lead to a competitive advantage compared to other producers.

\section{Acknowledgment}

One of the authors (GWB) would like to thank Gosse Boxhoorn of Solland Solar Energy for his excellent help and kind hospitality during his internship.

\section{References}

Andersson, B.A., 2000. Materials availability for large-scale thin-film photovoltaics. Progress in Photovoltaics: Research and Applications 8, 61-76.

Andersson, B.A., Jacobsson, S., 2000. Monitoring and assessing technology choice: the case of solar cells. Energy Policy 28, 1037-1049. 
Green, M.A., 2006. Consolidation of thin-film photovoltaic technology: the coming decade of opportunity. Progress in Photovoltaics: Research and Applications 14, 383-392.

Hegedus, S., 2006. Thin-film solar modules: the low cost, high throughput and versatile alternative to $\mathrm{Si}$ wafers. Progress in Photovoltaics: Research and Applications 14, 393-411.

Hirschman, W.P., Schmela, M., 2006. Silicon shortage - so what! Market survey on cell and module production 2005. Photon International March 100-125.

Rogol, M., Fisher, B., 2005. Sun Screen II: Investment Opportunities in Solar Power. CLSA.
Solarbuzz, 2006. Solar module price highlights website: 〈http://www. solarbuzz.com/ModulePrices.htm $\rangle$. Accessed in April 2006.

Swanson, R.M., 2006. A vision for crystalline silicon photovoltaics. Progress in Photovoltaics: Research and Applications 14, 443-453.

Unzalu, H., 2005. Capacity and Market Potential for Grid-Connected Systems by 2010. EPIA Workshop, Frankfurt, Germany.

Utterback, J.M., Suárez, F.F., 1993. Innovation, competition, and industry structure. Research Policy 22, 1-21.

Zweibel, K., 2005. The terawatt challenge for thin-film PV. Technical Report NREL/TP-520-38350. 